charge saturation current is in the neighbourhood of $20 \mathrm{ma}$. The optimum emission for the maintenance of the $130 \mathrm{~cm}$. Barkhausen-Kurz wave is fairly constant at $16 \mathrm{ma}$. for variations of the tuning cireuit, except at points $A$ (Fig. 2, previous letter), where it drops to 14 ma., corresponding to the drop in wavelength noticeable at these points. In the BarkhausenKurz zone, therefore, the oscillations are a maximum in the neighbourhood of space charge saturation of the grid current characteristic, in agreement with the results of Tank and Schiltknecht mentioned by Mr. Megaw. The secondary optimum emission value maintaining approximately the same wave-length is $8 \mathrm{ma}$. The emission range for optimum maintenance

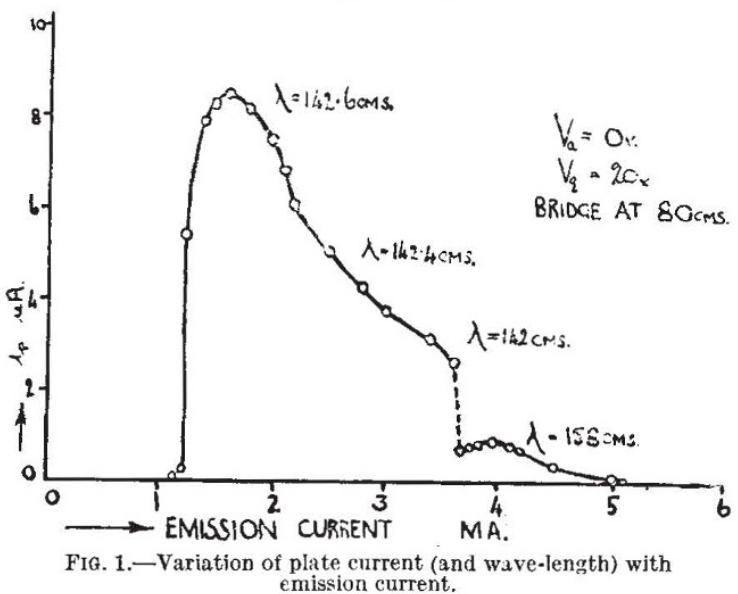

of the Gill-Morrell oscillations is continuous from $1 \mathrm{ma}$. to $11 \mathrm{ma}$., the wave-lengths extending from $90 \mathrm{~cm}$. to $170 \mathrm{~cm}$. The emission for optimum maintenance of a wave-length of $130 \mathrm{~cm}$. in this zone is $3 \mathrm{ma}$.

With the tuning bridge fixed in such a position as to offer a wave-length suitable for maintenance in the Gill-Morrell zone and variation of emission current, usually a sudden change in plate current, together with a change in wave-length, is noticed as the oscillations change from one type to the other. A clear example is shown in Fig. 1.

It is not at present possible to offer a full explanation of the existence of the two zones. However, it has been shown ${ }^{1}$ that electron oscillations can occur in the grid-anode space when it is space charge saturated, and in the valve used the dimensions were such as to permit this state to exist. If, then, oscillations can occur in the anode-cathode space as well, there would appear to be sufficient justification for postulating the existence of two types of oscillations. Fundamentally, no doubt, they are due to the same basic cause, and if in his forthcoming paper $\mathrm{Mr}$. Megaw co-ordinates the various conflicting experimental results, a distinct advance will have been made.

Munieipal College,

West Ham, E.15,

Feb. 15.

1 Gill, (a) A Space Charge Effect, Phil. Mag., Ser. 6, 49, 993; 1925 : (b) Electrical Oscillations of Very Short Wave-length, Phil. Mag., Ser. $7,12,843 ; 1931$.

\section{Light as a Factor in Sexual Periodicity}

REFERRING to the recent papers and communications of Dr. J. R. Baker and Mr. R. M. Ranson and Prof. T. H. Bissonette, read before the Royal Society, Feb. 4, Dr. Marshall ${ }^{1}$ suggests that the conclusion concerning light as a factor governing sexual periodicity involves a principle of wide application.
In view of this remark, it may be of some general interest to biologists to know that so far as the flowering plants are concerned this holds true.

Since a brief account of the earlier work on these lines was published in $1924,{ }^{2}$ further investigations have been carried out, and more than one hundred varieties and species have now been tested in Great Britain ; whilst in America, Russia, and elsewhere similar work has been done. The results have appeared in various botanical periodicals.

Briefly, it appears that the period of light exercises a profound influence upon the habit of growth, and determines whether many plants flower or remain in the vegetative condition. Under an unfavourable period of light, the formation of sexual organs may be suppressed for very long periods during which vegetative growth continues (Garner and Allard). The flowering plant is so organised morphologically that the response can be strictly localised to one part (Knott). The distribution of the sexual organs in the plant may also be controlled in another manner, as, for example, in hemp, where 'sex reversal' may occur; or in cucumber, where the sex ratio may be modified as a result of the influence of the period of light (Schaffner).

All observers record that the utilisation of the food products, whether in storage or in rapid growth, reflects the operation of this factor, which may also govern the rate of tuber formation (Maximov).

I am unaware that much information has as yet been collected from studies made with cryptogams. However, in the Hepaticæ (Liverworts) the forma. tion of sexual organs and their supporting tissues is at least partially controlled by this factor (Wann).

Possibly the well-known periodicity of the plankton (diatoms, peridineans, and crustaceans) would also provide an interesting series of observations when studied under varying conditions of light and constant temperature, salinity, etc. M. A. H. TINCKER.

Royal Horticultural Society, Wisley, March 5.

1 NATURE, 129, 344 ; March 5, 1932.

M. A. H. Tincker, NATURE, 114, 350 ; Sept. 6, 1924

With reference to the letter of Dr. F. H. A. Marshall on the above subject, ${ }^{1}$ I should like to direct attention to the relation of sexual maturity in marine invertebrates to the phases of the moon, a relation which was stated to exist many years ago and seemed at first scientifically incredible and imaginary, but which has been more recently verified by exact research carried out by several competent marine zoologists. The most famous case is that of the Palolo worm, Eunice viridis, the sexually mature posterior parts of which swarm at the surface of the sea off the islands of Samoa and Fiji in the mornings of the seventh, eighth, and ninth days after the full moon of November. The most recent paper on the subject is that by Silvio Ranzi of the Zoological Station of Naples. ${ }^{2}$ In many other species of Polychrta the sexual maturity and discharge of mature ova and sperms has been shown to synchronise with particular days of the lunar cycle, but in some localities certain species show no evidence of such a relation.

Ranzi's own researches were made on Platynereis dumerilii, in which he found that mature individuals occur at Naples from March to November, but that the greatest number of spawning individuals occurred on the third day after the full moon. Sexual maturity is thus not confined to one lunar month of the year in all cases as in the Palolo, but the sexual cycle is affected by the lunar cycle.

No. 3258, VoL. 129] 